\title{
Investigating the performance of hydroponic nutrient solutions as potential draw solutions for fertilizer drawn forward osmosis
}

\section{Mohamed Bassiouny}

The American University in Cairo

\section{Peter Nasr}

The American University in Cairo

Hani Sewilam ( $\square$ sewilam@lfi.rwth-aachen.de)

RWTH Aachen University https://orcid.org/0000-0001-9690-1652

\section{Research Article}

Keywords: Brackish groundwater, Desalination, Draw Solution, Fertilizer Drawn Forward Osmosis, Forward Osmosis, Hydroponic Nutrient Solution.

Posted Date: July 20th, 2021

DOl: https://doi.org/10.21203/rs.3.rs-278796/v1

License: (c) (i) This work is licensed under a Creative Commons Attribution 4.0 International License. Read Full License

Version of Record: A version of this preprint was published at Environmental Science and Pollution Research on February 15th, 2022. See the published version at https://doi.org/10.1007/s11356-02218701-5. 
Investigating the performance of hydroponic nutrient solutions as potential draw solutions for fertilizer drawn forward osmosis Mohamed Bassiouny ${ }^{1}$. Peter Nasr ${ }^{2}$. Hani Sewilam ${ }^{3,4, *}$

\author{
${ }^{1}$ m.bassiouny@aucegypt.edu, M.Sc. student, Center for Applied Research on the Environment and Sustainability (CARES), \\ School of Science and Engineering, The American University in Cairo, AUC Avenue, P.O. Box 74, New Cairo 11835, \\ Egypt. \\ 2 pnasr@aucegypt.edu, Research Consultant, Center for Applied Research on the Environment and Sustainability \\ (CARES), School of Science and Engineering, The American University in Cairo, AUC Avenue, P.O. Box 74, New Cairo \\ 11835, Egypt. \\ ${ }^{3}$ sewilam@aucegypt.edu, Professor and Director, Center for Applied Research on the Environment and Sustainability \\ (CARES), School of Science and Engineering, The American University in Cairo, AUC Avenue, P.O. Box 74, New Cairo \\ 11835, Egypt. \\ ${ }^{4}$ sewilam@lfi.rwth-aachen.de, Managing Director, UNESCO Chair in Hydrological Changes and Water Resources \\ Management, RWTH Aachen University, Germany. \\ * Corresponding Author
}

\title{
Abstract
}

This research project aims at investigating the performance of hydroponic nutrient solutions as draw solutions for desalination using the fertilizer drawn forward osmosis (FDFO) process. Six different lettuce and leafy greens hydroponic nutrient stock solutions were prepared according to the literature and used in this study and tested on a bench-scale forward osmosis unit as draw solutions for the process. The feed solution for the process was De-Ionized water mixed with $\mathrm{NaCl}$ in different concentrations, to represent different salinities of brackish groundwater. The draw efficiency of each solution was measured based on water flux, specific reverse solute flux, water recovery, and salt rejection. It was concluded that of the six tested nutrient solutions, the "Resh Florida, California" solution is the recommended solution to be used as draw solution for fertilizer drawn forward osmosis, due to its high performance in terms of water recovery $(15.75 \%)$, flux $\left(11 \mathrm{l} / \mathrm{m}^{2} / \mathrm{h}\right)$, salt rejection (92\%) and SRSF (highest recorded SRSF for a specific ion $\left(\mathrm{SO}_{4}{ }^{2-}\right)$ was $\left.7.3 \mathrm{~g} / \mathrm{l}\right)$, as well as its low cost, relative to the other highly performing draw solution "Chekli" (\$1.07/l vs. \$3.73/l).

\section{Keywords}

Brackish groundwater, Desalination, Draw Solution, Fertilizer Drawn Forward Osmosis, Forward Osmosis, Hydroponic Nutrient Solution.

\section{Declarations}

\section{Ethics Approval and Consent to Participate}

Not applicable

\section{Consent for Publication}

Not applicable

\section{Availability of Data and Materials}

The datasets used and/or analysed during the current study are available from the corresponding author on reasonable request.

\section{Competing Interests}

The authors declare that they have no competing interests.

\section{Funding}

Funding for this research was provided by the Center for Applied Research on the Environment and Sustainability, and the American University in Cairo.

\section{Authors' Contributions}

- M.B., P.N., and H.S. conceived and planned the experiments.

- M.B. and P.N carried out the experimental setup.

- M.B. carried out the experiments and the collection of data.

- M.B, P.N, and H.S. contributed to the interpretation of the results. 
- $\quad$ M.B. took the lead in writing the manuscript.

- M.B., P.N., and H.S. provided critical feedback and helped shape the research, analysis, and manuscript.

\section{Acknowledgements}

The authors would like to thank Porifera Inc. for providing the membrane and the bench-scale crossflow filtration unit.

\section{Introduction}

Water is among the most essential natural resources, and is utilized in nearly all human activities; it is necessary for domestic use, agriculture and industry, is one of the sustainers for ecosystems, and sometimes even is a hazard, such as in the cases of floods and droughts (Anandhi and Kannan, 2018). The water cycle is affected by many factors, including pollution, land use changes, population growth, climate change, urbanization, and industrial growth (Navarro-Ortega et al., 2015; Koutroulis et al., 2013). Globally, water demand is projected to increase by $55 \%$ by the year 2050, mainly due to growing demands from manufacturing (increasing by about $400 \%$ ), thermal electricity generation (increasing by about 140\%) and domestic use (increasing by about 130\%) (Shahzad, Burhan, Ang and Ng, 2018).

Water is the most essential resource for agricultural production and is very critical to food security; irrigated agriculture forms about $20 \%$ of the total cultivated land and it contributes about $40 \%$ of the total global food production (The World Bank, 2020). Agriculture is the biggest consumer of freshwater ("blue" water), where almost $90 \%$ of diverted freshwater in the world is used for irrigated agriculture (Traitler et al., 2018). This led to the introduction of the Water-Energy-Food Nexus, which is a concept that is central to sustainable development; the tangled connection between those 3 crucial domains means that managing water resources is essential for food security, while water resources are affected by climate change, which in turn, is affected by global energy usage and production.

Many societies now face the issue of water scarcity, which is a situation defined as having the water availability in a country or region be less than $1000 \mathrm{~m}^{3} / \mathrm{person} / \mathrm{year}$ (Pereira, Cordery and Iacovides, 2009). Almost a quarter of the human population, approximately 1.6 billion people, live under water scarcity, and this number may double in two decades (Roson and Damania, 2017). It is also projected that by 2050, more than $40 \%$ of the world's population will be living in areas of severe water stress (Shahzad et al., 2018).

In order to combat shortages in clean freshwater resources, more countries are resorting to desalination, where desalination widens the potential of utilisation of water resources by producing freshwater from saline or brackish natural water sources (Burns et al., 2015). Water desalination processes are categorized into thermal desalination and membrane desalination. Thermal desalination processes are generally characterized by high costs and being energy intensive, hence, new facilities have been designed to utilize more membrane desalination processes (Cotruvo, 2016). On the other hand, membrane desalination technologies have started to gain traction as the preferred desalination technology in the past few decades, due to advancements in membrane technologies. The commercially established membrane desalination technologies are RO, NF, and ED (Burn et al. 2015).

Hence, recent efforts have been directed at developing less energy and capital costly desalination processes, such as Forward Osmosis (FO). FO has the advantage of operating without the need for hydraulic energy, and operating at a lower pressure than RO, which decreases the capital cost (Shon, Phuntsho, Zhang and Surampalli, 2015). The disadvantages of FO are that the resultant of the process is a diluted draw solution, from which freshwater would need to be separated, which requires further processing. Moreover, membrane technologies and draw solutions are still in need of further development before FO could be commercially widespread (Phuntsho et al., 2012a; Nasr and Sewilam, 2015).

Fertilizer Drawn Forward Osmosis (FDFO), demonstrated in figure (1), isan application of FO in which the draw solution is a highly concentrated fertilizer solution, which is diluted by drawing freshwater from the feed solution (saline or brackish water). It is a method of overcoming the inherent disadvantage of FO, in which the resultant end product is diluted draw solution, not freshwater. This diluted draw solution could hypothetically be used directly to grow agricultural crops, if it was diluted to the required concentration for agriculture. 
FDFO technology can be integrated with modern agriculture, such as Hydroponics, to capitalize on water and energy savings. Hydroponics, demonstrated in figure (2) is defined as the practice of growing plants without using soil, either by using an inert medium, such as gravel, sand, peat, vermiculite, pumice, perlite, coco coir, sawdust, rice hulls, or other substrates, to which a nutrient solution that contains all the essential elements needed by the plant is provided (Resh, 2012). Hydroponic systems are divided into liquid systems, which have no supporting medium for the plant, and aggregate systems, which have a solid medium for support (Jensen, 1997).

\section{Theory}

In the following sections, the theory behind forward osmosis and hydroponic agriculture will be explored.

\section{Forward Osmosis}

When investigating processes related to forward osmosis, 3 main parameters have to be examined. These parameters are: Water flux, Reverse Solute Flux, and Salt Rejection.

\section{Flux}

When a feed solution of a low osmotic pressure is separated from a draw solution of high osmotic pressure by a semi-permeable membrane, the concentration of the draw solution decreases and the concentration of the feed solution increases due to the solvent transfer caused by the difference in osmotic pressure $(\Delta \pi)$ (Shon et al., $2015)$, where osmotic pressure $(\pi)$ can be defined as "the amount of pressure that is required to prevent the transport of pure water through an ideal semi-permeable membrane into a specific solution" (Mulder, 1996, as cited in Shon et al., 2015).

The model that is commonly used to describe mass transfer through an FO membrane is the solutiondiffusion model; in an FO process, the water flux $\left(\boldsymbol{J}_{\mathrm{v}}\right)$ and solute flux $\left(\boldsymbol{J}_{\mathrm{s}}\right)$ can be calculated by (Lee et al., 1981, as cited in Shon et al., 2015):

$$
\begin{gathered}
J_{v}=A(\sigma \Delta \pi-\Delta P) \\
J_{s}=B \Delta C
\end{gathered}
$$

where $\mathrm{A}$ is the membrane water permeability coefficient, $\mathrm{B}$ is the solute permeability coefficient, $\mathrm{C}$ is the solute reflection coefficient, usually assumed to be unity; $\Delta P$ is the applied hydraulic pressure, which is zero $(\mathrm{P}=0)$ in the FO process, and hence, water flux can be expressed as the multiplication of the membrane water permeability and the difference in osmotic pressure.

$$
J_{v}=A\left(\pi_{\text {draw }}-\pi_{\text {feed }}\right)
$$

where $\pi_{\text {draw }}$ and $\pi_{\text {feed }}$ are the osmotic pressures of the draw solution and feed solution, respectively (Shon et al., 2015).

Equation (3), however, only describes the theoretical ideal situation. In experiment, the FO water flux is found to be much lower than that ideal value of product of membrane water permeability coefficient and the osmotic potential difference of the draw and feed solutions, due to the concentration polarization phenomenon (Shon et al., 2015). In FO process, concentration polarization exists on the both external sides of the membrane when there are solutes in both the feed and draw solutions (Shon et al., 2015). The build-up of solutes on the feed side of the membrane is defined as concentrative external concentration polarization (concentrative ECP), while the depletion of solutes on the draw side of the membrane is referred to as dilutive ECP (McCutcheon and Elimelech, 2006, as cited in Shon et al., 2015). However, the effect of ECP, demonstrated in figure (3) on the FO flux is relatively small, and could be mitigated through manipulating the flux and mass transfer coefficient, through approaches such as adjusting the crossflow velocity, using spacers, vibrations, or ultrasound, etc. (Lee et al., 1981; Sablani et al., 2001; Cath et al., 2006, as cited in Shon et al., 2015).

A more severe problem compared to ECP that contributes to low FO water flux is internal concentration polarization (ICP) (Shon et al., 2015). Semi-permeable membranes often have a thicker and porous support layer underneath the thin selective layer, in order to provide enough support strength (Shon et al., 2015). The support layer often inhibits mass diffusion and hence, lead to the accumulation of a concentration polarization layer within it (Shon et al., 2015), which is the phenomenon that is referred to as ICP, and is demonstrated in figure (4). In FO, the asymmetric semi-permeable membrane can be installed with the active rejection layer (AL) facing either the draw solution (referred to as AL-DS) or the feed solution (AL-FS) (Shon et al., 2015). 

al., 2015):

In the ICP model, water flux can be modelled (Lee et al., 1981; Loeb et al., 1997; as cited in Shon et

Dilutive ICP (AL-FS):

$$
J_{v}=K_{m} \ln \left(\frac{A \pi_{\text {draw }}-J_{v}+B}{A \pi_{\text {feed }}+B}\right)
$$

$$
J_{v}=K_{m} \ln \left(\frac{A \pi_{\text {draw }}+B}{A \pi_{\text {feed }}+J_{v}+B}\right)
$$

where $A$ is water permeability coefficient; $B$ is solute permeability coefficient; and $K_{m}$ is the mass transfer coefficient, defined as:

$$
K_{m}=\frac{D}{S}
$$

where $D$ is the solute diffusion coefficient; $S$ is the structural parameter of membrane, defined as:

$$
S=\frac{\tau l}{\varepsilon}
$$

where $\tau, l$ and $\varepsilon$ are the tortuosity, the actual thickness and porosity of the porous support layer, respectively.

\section{Reverse Solute Flux (RSF)}

Reverse solute flux (RSF) is an important parameter to consider in the FO process; since a reverse diffusion of the draw solutes would cause an economic loss due to the inability to recover these draw solutes (Cath et al., 2006, as cited in Nasr and Sewilam, 2016). Moreover, reverse solute permeation increases the occurrence of fouling by creating complexes between draw and feed ions (Cath et al., 2006; Lay et al., 2010, as cited in Nasr and Sewilam, 2016). The FO solute flux can be determined by (Tang et al., 2010, as cited in Shon et al., 2015):

$$
J_{s}=\frac{B}{A \cdot \beta R_{g} T} J_{v}
$$

where $\beta$ is the van't Hoff coefficient; $R_{g}$ is the universal gas constant; $\mathrm{T}$ is the absolute temperature.

\section{Specific Reverse Solute Flux (SRSF)}

Specific reverse solute flux (SRSF) is the ratio between RSF and water flux. SRSF is a measurement that was created to signify the mass of draw solutes that was lost through reverse permeation per unit volume of water extracted from the FS (Cath et al., 2006, as cited in Nasr and Sewilam, 2015). SRSF can be calculated by using the equation below:

$$
\mathrm{SRSF}=\frac{J_{s}}{J_{v}}
$$

By combining equations (8) and (9), SRSF can be expressed as:

$$
S R S F=\frac{B}{A \cdot \beta R_{g} T}
$$

\section{Hydroponic Nutrient Solutions}

In hydroponic nutrient solutions, 3 main parameters guide the successful selection of solutions. These parameters are: The required nutrients for the plant, the solubility of the nutrient salts in water, and the concentration of each of these salts.

\section{Plant Nutrition}

In order to supply the plants with the essential elements in hydroponics, fertilizer salts are dissolved in water to form hydroponic nutrient solutions (Resh, 2012) and many researchers have developed basic formulae for nutrient solutions, such as Hoagland, Arnon, Robbins, Hewitt, Cooper, Steiner, Bollard, Middleton, Shive, and Tollens. These nutrient solutions are often referred to as standard nutrient solutions. While various fertilizer salts can be used in the nutrient solutions, the choice of salts is affected by their solubility (Resh, 2012). It is well established that the external concentration of each of the nutrients that is required to satisfy the internal demands of plants vary between different species; there cannot be a single nutrient solution that is effective under all 
circumstances (Smith, Johnston, and Cornforth, 1983). 16 elements have been identified as essential for the growth of higher plants, and they are divided into macronutrients $(\mathrm{H}, \mathrm{C}, \mathrm{O}, \mathrm{N}, \mathrm{K}, \mathrm{Ca}, \mathrm{Mg}, \mathrm{P}, \mathrm{S})$, which are those required in relatively large quantities, and micronutrients $(\mathrm{Cl}, \mathrm{Fe}, \mathrm{Mn}, \mathrm{B}, \mathrm{Zn}, \mathrm{Cu}, \mathrm{Mo})$, which as those required in smaller quantities (Resh, 2012) .

Solubility

Solubility of fertilizer salts is a property that dictates the concentration of the salt that remains in solution when dissolved in water; in hydroponics, fertilizer salts with a high solubility are necessary in order for them to remain in solution and be available to be absorbed by the plants (Resh, 2012).

Moreover, the proportion of ions that is provided by each of the salts is important to consider when designing the nutrient solution; for example, one molecule of calcium nitrate $\left(\mathrm{Ca}\left(\mathrm{NO}_{3}\right)_{2}\right)$ will yield one ion of calcium $\left(\mathrm{Ca}^{2+}\right)$ and two ions of nitrate 2( $\left.\mathrm{NO}_{3}^{-}\right)$(Resh, 2012), and depending on the type of plant that is being grown, different combinations and concentrations of fertilizer salts will have to be used in order to achieve optimum growth.

\section{Concentrations}

The amount of nitrogen $(\mathrm{N})$ in an ion of nitrate $\left(\mathrm{NO}_{3}{ }^{-}\right)$can be calculated by calculating the fraction that each element represents within its compound source, in order to calculate the conversion factor (Resh, 2012).

The conversion factors can be utilized to find the ppm concentration of each element that is obtained by dissolving a specific compound. For example, if $100 \mathrm{mg}$ of calcium nitrate $\left(\mathrm{Ca}\left(\mathrm{NO}_{3}\right)_{2}\right)$ is dissolved in $1 \mathrm{~L}$ of water, the concentration of $\mathrm{Ca}$ will be $24.4 \mathrm{mg} / \mathrm{L}$ ( $24.4 \mathrm{ppm}$ ) and the concentration of $\mathrm{N}$ will be $17.1 \mathrm{mg} / \mathrm{L}$ (17.1 $\mathrm{ppm})$. Table 1 lists the concentration of the elements in some of the standard hydroponic nutrient solutions.

\section{Materials and Methods}

The materials used in this study consist of the apparatus, which is the bench-scale crossflow filtration unit, the membrane, and the solutions used in each experiment.

\section{Apparatus}

For this experiment, a bench-scale crossflow filtration unit with an FO cell was used, illustrated in figure (5). On both sides of the membrane, two channels are connected to allow flow of feed solution on one side, and draw solution on the other side. Crossflows were operated in counter-current flow directions, by using a variable speed peristaltic pumps (Stenner, model 170DMP5, 25 psi, $1.7 \mathrm{bar}, 50 \mathrm{~Hz}$, USA). All solutions were kept at a temperature of $25{ }^{\circ} \mathrm{C}$ through a temperature water bath controlled by a heater/chiller (Polyscience temperature controller, model 9106A12E). Experiments were operated at a crossflow rate of $400 \mathrm{~mL} / \mathrm{min}$, which can be converted to a crossflow velocity of $8.5 \mathrm{~cm} / \mathrm{s}$. The change in the volumes of the DS in the DS tank and FS in the FS tank were continuously recorded by placing the DS and FS on a digital mass scale, which was connected to a computer for online data logging at intervals of 3 minutes. This change of volume was used to calculate the water flux across the membrane.

The initial volume of both the DS and the FS was $250 \mathrm{~mL}$, and most experiments were run for 2.5 to 3 hours, since a stable flux was usually achieved after the first hour of operation. Experiments were conducted under (AL-FS) orientation, where the active layer was facing the feed solution

Water flux $J_{v}$ (in $\mathrm{L} / \mathrm{m}^{2} / \mathrm{h}$ ) was calculated using:

$$
J_{v}=\frac{\Delta V}{\text { membrane area } \times \text { time }}
$$

Solute flux was calculated as follows:

$$
J_{s}=\frac{\left(V_{i}-\Delta V\right) \times C_{s}}{\text { membrane area } \times \text { time }}
$$

Where $V_{i}$ is the initial volume of FS, $\Delta V$ is the total volume of water displaced from the FS to the DS, and $C_{S}$ is the concentration of the draw solutes in the FS at the end of the experiment.

The FO membrane that will be used in this study was purchased from Porifera Inc. Its active layer is made out of polyamide, and its support layer is made out of a porous hydrophilic polymer (Tayel, Nasr and Sewilam, 2019; Porifera Inc., 2015). The average total thickness of the membrane is $70 \pm 10 \mu \mathrm{m}$ (Tayel, Nasr and 
Sewilam, 2019; Porifera Inc., 2015). Properties of the membrane, as provided by the manufacturer, are listed in table 2 (Porifera Inc., 2015)

Moreover, since salt rejection is a crucial parameter in FO processes, it will be investigated by taking samples from the DS after every experiment, and analysing its $\mathrm{Na}^{+}$and $\mathrm{Cl}^{-}$ions; the following equation will be used to calculate salt rejection percentage (Nasr and Sewilam, 2016):

$$
\operatorname{Re}(\%)=\frac{C_{i}-\left(\frac{C_{p, D}\left(V_{i}+\Delta V\right)}{\Delta V}\right)}{C_{i}} \times 100
$$

where $C_{i}$ is the initial concentration of the ion in FS, $C_{p, D}$ is the final concentration of the ion in DS, $V_{i}$ is the initial volume of the DS and $\Delta V$ is the total volume of water that entered the DS from the FS (Nasr and Sewilam, 2016).

\section{Draw Solutions}

The chemicals and fertilizer salts were provided by the AUC WEF (Water-Energy-Food) Nexus Labs, and some additional salts were purchased from Science and Technology Center, Egypt. All chemicals used were laboratory \& reagent grades.

The lettuce and leafy green nutrient solutions formulae were selected from table 1 (Resh, 2012). The formulae selected are:

- $\quad$ Dr. H.M. Resh, Tropical - Dry Lettuce - referred to as (RTD)

- $\quad$ Dr. H.M. Resh, Tropical - Wet Lettuce - referred to as (RTW)

- $\quad$ Dr. H.M. Resh Lettuce, Florida (1989), California (1993) - referred to as (RF)

- $\quad$ Dr. H.M. Resh Lettuce, Anguilla, B.W.I (2011) - referred to as (RA)

- Optimum Grow - twin pack hydroponic nutrient solution used in Chekli's paper, according to the formula of macro and micro nutrient mentioned in the paper (Chekli et al., 2017) - referred to as (CHE).

- $\quad$ Robbins (1946). This solution satisfies the ratio of macro and micro nutrient recommended for growing lettuce in Mediterranean climate in the summer, shown below in table 3 (Resh, 2012) - referred to as (ROB)

Listed in table 4 are the macro and micro nutrient compositions (in $\mathrm{mg} / \mathrm{L}$ ) of the selected formulae:

Stock solutions are prepared in different strengths, depending on the size of the application. 50, 100, 200 are the most common, but strengths as high as 800 times can be used in large scale applications. Stock solutions are then diluted accordingly when used for hydroponic agriculture (Resh, 2012).

Hydroponic nutrient stock solutions are prepared in two solutions; A and B solutions. This is done to avoid any precipitation that might occur between different compounds, such as Nitrates and Sulphates. The problem of precipitation is especially likely when these compounds are used in very high concentrations (eg. for 100 and 200 strength solutions). Solution B of each nutrient solution was selected as the draw solution for the forward osmosis process, due to the fact that they include all macronutrients ( $\mathrm{N}, \mathrm{P}, \mathrm{K}, \mathrm{Ca}, \mathrm{Mg}, \mathrm{S}$ ), as well as most micronutrients ( $\mathrm{Mn}, \mathrm{B}, \mathrm{Zn}, \mathrm{Cu}, \mathrm{Mo})$. While solution A was found to have higher theoretical osmotic pressure in some solutions, the presence of high concentrations of $\mathrm{Ca}$ in A solutions could lead to excessive fouling of the membrane if diffusion to the feed solution occurs through bridging mechanisms that occur with organic compounds (Chekli et al., 2017a).

In order to prepare the stock solutions, calculations for each formulae were made, in order to determine how much of each of the available compounds should be used to achieve the required ratio. Solutions were prepared in 100 times strength. Listed in table 5 the chemicals that make up each solution, as well as the theoretical osmotic pressure of each solution, estimated using Lenntech osmotic pressure calcuator (Lenntech, n.d.):

It is worth noting that solution A contains high amount of Calcium, while solution B contains the phosphates and sulphates, which can both form insoluble precipitations if mixed in such concentrated form. Hence, solutions A and B have to be processed separately in FO in parallel stages, or only one of the solutions 
can be used as DS for FO, and the other can be later added in diluted form to complete the nutrient solution (Chekli et al., 2017). The latter option was opted for, in order to avoid fouling of the membrane caused by the $\mathrm{Ca}$ in A solutions.

Shown in figure (6) is the cost per liter of each of the draw solutions used, according to Science and Technology Center, Egypt. It is worth noting that these prices are for laboratory/reagent grade chemicals. In an industrial scale application, technical grade chemicals would be used, which could be obtained for prices lower than those listed below

\section{Experimental Plan}

Feed solutions were prepared by dissolving $\mathrm{NaCl}$ in $\mathrm{DI}$ (De-Ionized) water in 3 concentrations: 5,10 and 15 $\mathrm{g} / \mathrm{L}$. These concentrations represent different salinities of brackish groundwater. Six different hydroponic nutrient solutions were investigated as DS for the process. 18 experiments were carried out. All solutions were prepared by dissolving the salts in DI water, and stirred with a magnetic stirrer for at least 30 minutes, in order to ensure complete dissolution. Solutions were then stored in plastic bottles.

For each experiment, $250 \mathrm{~mL}$ of both the FS and DS were poured into plastic bottles, and both were weighed using a digital scale. Moreover, TDS was measured by using a portable TDS and EC meter (Hach HQ40D multi). Then, bottles were covered with Parafilm, in order to minimise evaporation. Both bottles were then placed on the crossflow filtration unit, and the unit was run for 2.5 to 3 hours for each experiment. After the experiment was over, the system was drained from the remaining feed and draw solutions into the corresponding beakers. After the system was completely drained of draw and feed solutions, which usually took around 20 to 30 minutes, the bottles were carefully removed and replaced with bottles of DI water. The system was then operated again with DI water, in order to flush the membrane. This flushing was repeated 3 to 4 times, and each flush was between 10 and 20 minutes. The final weights and TDS of the feed and draw solutions was then measured and recorded. Samples of each solution before and after processing was stored for ion analysis.

\section{Water Recovery}

The volume of water recovered through forward osmosis was calculated through the weight of FS and DS before and after each experiment. The results are shown in figure (7). The highest water recovery was achieved in Chekli solution, with a recovered pure water volume of $39.57 \mathrm{ml}$, which represents a recovery percentage of $15.8 \%$. This can be explained by its high osmotic pressure, which is demonstrated in table 5. Water recovery percentage is shown in figure 7, and was calculated by finding the ratio between the volume of water recovered through FO and the initial volume of the FS.

\section{Water Flux}

Water flux was calculated using equation (11). The average water flux for each draw solution is shown in figure (8). The highest recorded average water flux (12.28 LMH) was observed in the CHE solution when the feed solution was $5 \mathrm{~g} / \mathrm{l} \mathrm{NaCl}$ (FS1), due to the high osmotic pressure (16.43 bar). The lowest value of average water flux (1.5 LMH) was observed in RA draw solution when coupled with a feed solution of $15 \mathrm{~g} / \mathrm{l} \mathrm{NaCl}$ (FS3), which is expected due to the low osmotic pressure of this solution (13.57 bar). While RF had a higher theoretical osmotic pressure, it exhibited slightly lower flux than CHE, and this could be explained by biofouling or scaling occurring in the membrane over the period of operation. It has been proven that while having the active layer of the membrane be facing the feed side (AL-FS) generally generates a more stable water flux performance than (AL-DS) orientation, the ICP levels are also more severe in this orientation (AL-FS), which leads to relatively lower water flux (Zhang et al., 2012).

Water flux was plotted against the TDS of each of the draw solutions. As predicted, the draw solution with the highest TDS exhibited the highest water flux, since water flux is dependent on the osmotic pressure of the draw solution $\left(\pi_{\text {draw }}\right)$. The correlation between flux and TDS is logarithmic, with $\mathrm{R}^{2}$ being between 0.51 and 0.74 , indicating a good fit for the logarithmic model. This is demonstrated in figure (9). 
fit. It is noticed that flux starts very high in the beginning, then decreases with a high slope till around 40 minutes, at which point, flux becomes almost constant. It is also noticed that the water flux had not reached zero yet, indicating that osmotic equilibrium was not yet reached, and the process could still be operated for a longer period of time. It is also worth noting that in the case of using the $15 \mathrm{~g} / \mathrm{l} \mathrm{NaCl}$ solution as FS, and RTD as DS,

flux increased after 60 minutes, instead of the expected behaviour of falling off. This could be explained by some membrane scaling that was removed by the flow of both solutions on the membrane.

\section{Specific Reverse Solute Flux}

Specific reverse solute flux (SRSF) was calculated through equations $9 \& 10$ for $\mathrm{SO}_{4}{ }^{2-}, \mathrm{Mg}^{2+}, \mathrm{K}^{+}, \mathrm{PO}_{4}{ }^{3-}, \mathrm{NH}_{4}{ }^{+}$, and $\mathrm{NO}_{3}{ }^{-}$, and plotted vs. flux in figure 13. Figure 14 demonstrates detailed graphs for the separate ions. It can be observed that $\mathrm{SRSF}$ for $\mathrm{SO}_{4}$ and $\mathrm{NO}_{3}$ was significantly higher than the other ions. It should be noted that the higher the membrane selectivity, the lower the SRSF value should be. From figure 13, it is noticed that at high flux ( $\geq 9 \mathrm{~L} / \mathrm{m}^{2} / \mathrm{h}$ ), SRSF values for all ions range between 0 and $6 \mathrm{~g} / \mathrm{L}$. Meanwhile, at lower fluxes $\left(<9 \mathrm{~L} / \mathrm{m}^{2} / \mathrm{h}\right)$, SRSF values for all ions are relatively higher, with the highest value being $23 \mathrm{~g} / \mathrm{L}$. This indicates a high reverse flux of the draw solutes at low water flux, which is an issue inherent to forward osmosis. The attraction between the different ions could also have generated an additional slight driving force across the membrane (Kim et al. 2015; Tan and Ng 2008, as cited in Nasr and Sewilam, 2015). Moreover, dilutive ECP \& ICP might have also contributed in the reverse solute flux. This could be explained by the orientation of the membrane utilized (ALFS), which might have led to accumulation of ions on the draw side of the membrane.

\section{Salt Rejection}

FS ions $\left(\mathrm{Na}^{+}\right.$and $\left.\mathrm{Cl}^{-}\right)$were calculated using equation (13), and the results are shown in figure (15). As can be observed in figure 15, high rejection of FS ions was achieved in almost all draw solutions, which indicates that the used membrane has high selectivity against feed ions. However, ROB solution achieved a lower rejection, when operated with FS3 (15 g/l NaCl due to its low osmotic pressure (12.94 bars), which lead to the decrease in the osmotic potential gradient $(\Delta \pi)$, which is the main source of force in the FO process, which in turn affects the rejection of the membrane.

\section{Conclusion}

This study investigated the performance of six hydroponic draw solutions as draw solutions for the FDFO process. The feed solution for the process was chosen to be three different concentrations of $\mathrm{NaCl}$, in order to represent different salinities of brackish groundwater.

This was done in order to assess the viability of utilizing forward osmosis to facilitate hydroponic agriculture in arid regions, by diluting the nutrient solutions using water recovered from groundwater through forward osmosis. Performance of the draw solutions was assessed by determining the water flux, reverse solute flux, and the forward rejection of the salt ions in the feed solution. Moreover, the cost per litre of each of the solution was estimated. It was concluded that the TDS of the nutrient solution and the water flux can be related logarithmically.

From figure 10, it can be concluded that as a general rule of thumb, when comparing between different hydroponic nutrient solutions, it is expected that the nutrient solution with the higher TDS would usually have the higher water flux. This is due to the fact that the main driving force in forward osmosis is the osmotic potential gradient between the FS and the DS $\left(\pi_{\text {draw }}-\pi_{\text {feed }}\right)$, as per equation (3). However, the interactions between the different salt ions could possibly generate minor driving forces, which could affect the overall water flux. The water flux of each of the draw solutions during each individual experiment could have also been affected due to membrane scaling caused by monovalent ions (Phuntsho et al., 2014).

SRSF values for all salt ions were higher at low fluxes, and lower when operated at high flux so they had an inverse relation. Moreover, it can be observed that across all draw solutions, SRSF values increased as the concentration of the FS increased. This can be justified by the relation between SRSF and water flux. Salt

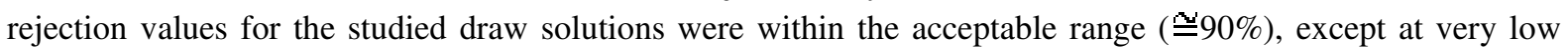
osmotic potential gradients. For example, for the Robbins solution (TDS $=26.1 \mathrm{ppt}$ ) and FS 3 (TDS $=17.15$ ppt), the salt rejection for $\mathrm{Na}^{+}$was $83 \%$ and for $\mathrm{Cl}^{-}$was $80 \%$.

According to the work done in this research, it is suggested to use the Resh Florida, California hydroponic nutrient solution, which is suitable for the cultivation of lettuce and leafy greens, as a draw solution for FDFO. This nutrient solution was selected due to its high performance and comparatively low price. While 
the Chekli solution performed better in terms of water flux (12.28 vs $11 \mathrm{LMH})$, the cost per liter of the Resh 379 Florida solution is $28 \%$ that of the Chekli solution (\$1.07/1 vs. \$3.73/1). Moreover, the SRSF values for the Resh 380 Florida solution were comparable to those of the Chekli solution in all salt ions.

Future research in the field can be directed at:

- $\quad$ Utilizing a real brackish groundwater sample as the FS for the process.

- Experimenting with other leafy greens nutrient solutions from the literature

- Utilizing nutrient solutions designed for crops other than leafy greens, such as for tomatoes or pepper.

- Experimenting with different concentrations of stock solutions for the same nutrient solution, such as 200 and 800 strength stock solutions.

- $\quad$ Testing the Resh Florida/California (RF) nutrient solution as a draw solution on the pilot-scale.

- $\quad$ Life-cycle assessment of the membrane during FO.

- Growing crops with the resultant draw solutions.

- Experimenting with different types of membranes. 


\section{References}

Abdel-Shafy, H. I., \& Kamel, A. H. (2016). Groundwater in Egypt Issue: Resources, Location, Amount, Contamination, Protection, Renewal, Future Overview. Egyptian Journal of Chemistry, 59(3), 321362. doi: 10.21608/EJCHEM.2016.1085

Allam, A. R., Saaf, E. J., \& Dawoud, M. A. (2003). Desalination of brackish groundwater in Egypt. Desalination, 152(1-3), 19-26. doi: 10.1016/S0011-9164(02)01044-5

Aly, A. A. (2015). Hydrochemical characteristics of Egypt western desert oases groundwater. Arabian Journal of Geosciences, 8(9), 7551-7564. doi: 10.1007/s12517-014-1680-8

Amin, G., Nasr, P., \& Sewilam, H. (2020). An Experimental Study on Draw Solution Performance in Fertilizer Drawn Forward Osmosis under Water Energy Food Nexus Framework in Egypt. Manuscript submitted for publication, Cairo. Retrieved October 05, 2020.

Anandhi, A., \& Kannan, N. (2018). Vulnerability assessment of water resources - Translating a theoretical concept to an operational framework using systems thinking approach in a changing climate: Case study in Ogallala Aquifer. Journal of Hydrology, 557, 460-474. https://doi.org/10.1016/j.jhydrol.2017.11.032

Arnon, D. (1938). Microelements in Culture-Solution Experiments with Higher Plants. American Journal of Botany, 25(5), 322-325. Retrieved from http://www.jstor.org/stable/2436754

Ataee, A., Alanezi, A. A., \& Hawari, A. H. (2018). Forward osmosis feasibility and potential future application for desalination. In V. G. Gude (Ed.), Emerging Technologies for Sustainable Desalination Handbook (pp. 35-54). essay, Elsevier. https://www.sciencedirect.com/.

Baba, A., Tayfur, G., Gündüz, O., Howard, K. W., Friedel, M. J., \& Chambel, A. (2011). Climate Change and its Effects on Water Resources (Vol. 3). Springer. Retrieved November 14, 2020, from https://linkspringer-com.libproxy.aucegypt.edu/book/10.1007\%2F978-94-007-1143-3

Baker, R. W. (2012). Membrane technology and applications. ProQuest Ebook Central https://ebookcentral.proquest.com

Basic Hydroponic Systems and How They Work. (n.d.). Retrieved November 3, 2019, from https://www.simplyhydro.com/system/.

Basile, A., Cassano, A., \&amp; Rastogi, N. K. (2015). Advances in Membrane Technologies for Water Treatment Materials, Processes and Applications. Elsevier. https://doi.org/10.1016/C2013-0-16469-0

BOLLARD, E. (1966). A COMPARATIVE STUDY OF THE ABILITY OF ORGANIC NITROGENOUS COMPOUNDS TO SERVE AS SOLE SOURCES OF NITROGEN FOR THE GROWTH OF PLANTS. Plant and Soil, 25(2), 153-166. Retrieved from http://www.jstor.org/stable/42933226

Blandin, G., Verliefde, A. R. D., Tang, C. Y., \& Le-Clech, P. (2015). Opportunities to reach economic sustainability in forward osmosis-reverse osmosis hybrids for seawater desalination. Desalination, 363, 26-36. https://doi.org/10.1016/j.desal.2014.12.011

Burn, S., \& Gray, S. (Eds.). (2015). Efficient desalination by reverse osmosis : A guide to ro practice. Retrieved from https://ebookcentral.proquest.com

Burn, S., Hoang, M., Zarzo, D., Olewniak, F., Campos, E., Bolto, B., \& Barron, O. (2015). Desalination techniques - A review of the opportunities for desalination in agriculture. Desalination, 364, 2-16. doi:10.1016/j.desal.2015.01.041

Campione, A., Gurreri, L., Ciofalo, M., Micale, G., Tamburini, A., \& Cipollina, A. (2018). Electrodialysis for water desalination: A critical assessment of recent developments on process fundamentals, models and applications. Desalination, 434, 121-160. doi:10.1016/j.desal.2017.12.044

Cath, T. Y., Childress, A. E., \& Elimelech, M. (2006). Forward osmosis: Principles, applications, and recent developments. Journal of Membrane Science, 281(1-2), 70-87. doi: 10.1016/j.memsci.2006.05.048

Chekli, L., Kim, J. E., El Saliby, I., Kim, Y., Phuntsho, S., Li, S., ... Shon, H. K. (2017a). Fertilizer drawn forward osmosis process for sustainable water reuse to grow hydroponic lettuce using commercial nutrient solution. Separation and Purification Technology, 181, 18-28. doi: 10.1016/j.seppur.2017.03. 008

Chekli, L., Kim, Y., Phuntsho, S., Li, S., Ghaffour, N., Leiknes, T. O., \& Shon, H. K. (2017b). Evaluation of fertilizer-drawn forward osmosis for sustainable agriculture and water reuse in arid regions. Journal of Environmental Management, 187, 137-145. doi: 10.1016/j.jenvman.2016.11.021

Chekli, L., Pathak, N., Kim, Y., Phuntsho, S., Li, S., Ghaffour, N., . . . Shon, H. K. (2018). Combining high performance fertiliser with surfactants to reduce the reverse solute flux in the fertiliser drawn forward osmosis process. Journal of Environmental Management, 226, 217-225. doi:10.1016/j.jenvman.2018.08.024

Cooper, A. J. (1975). Crop production in recirculating nutrient solution. Scientia Horticulturae, 3(3), $251-258$. doi: 10.1016/0304-4238(75)90008-4 
Cotruvo, J. (2016, October 7). Desalination Basics. Retrieved October 13, 2019, from https://www.watertechonline.com/desalination-basics-thermal-membrane/.

Dakkak, A. (2017, July 22). Egypt's Water Crisis - Recipe for Disaster. Retrieved September 28, 2019, from http://www.ecomena.org/tag/water-scarcity-in-egypt/.

Damkjaer, S., \& Taylor, R. (2017). The measurement of water scarcity: Defining a meaningful indicator. A Journal of the Human Environment, 46(5), 513-531. doi: 10.1007/s13280-017-0912-z

Desalination Technology : Health and Environmental Impacts, edited by Joseph Cotruvo, et al., Taylor \& Francis Group, 2010. ProQuest Ebook Central, https://ebookcentral.proquest.com/lib/aucegypt/detail.action?docID=565856.

El Zayat, H. A., Sewilam, H., \& Nasr, P. (2019). Volume Reduction of Synthetic Brine Using Fertilizer Drawn Forward Osmosis for Irrigation: A Pilot-Scale Investigation (Unpublished master's thesis). The American University in Cairo.

Elsayed, H., Djordjević, S., Savić, D. A., Tsoukalas, I., \& Makropoulos, C. (2020). The Nile Water-FoodEnergy Nexus under Uncertainty: Impacts of the Grand Ethiopian Renaissance Dam. Journal of Water Resources Planning and Management, 146(11). doi:10.1061/(ASCE)WR.1943-5452.0001285

FAO. (20167). Aquastat. Retrieved October 18, 2019, from http://www.fao.org/nr/water/aquastat/countries_regions/Profile_segments/EGY-WU_eng.stm.

FAO. (n.d.). Water scarcity. Retrieved August 12, 2020, from http://www.fao.org/land-water/water/waterscarcity/en/

FAO. AQUASTAT - FAO's Global Information System on Water and Agriculture. Food and Agriculture Organization of the United Nations. http://www.fao.org/aquastat/en/overview/methodology/water-use.

FAO. Home Gardens/Vertical Farming, Hydroponics and Aquaponics. Food and Agriculture Organization of the United Nations. http://www.fao.org/land-water/overview/covid19/homegardens/en/.

Gilbert, N. (2012). Water under pressure. Nature, 483, 256-257. doi: 10.1038/483256a

Globalagriculture. (n.d.). Water. Retrieved November 18, 2020, from https://www.globalagriculture.org/reporttopics/water.html

Gosling, S. N., \& Arnell, N. W. (2016). A global assessment of the impact of climate change on water scarcity. Climatic Change, 134(3), 371-385. doi: 10.1007/s10584-013-0853-x

Gude, V. G. (Ed.). (2018). Emerging Technologies for Sustainable Desalination Handbook. Elsevier. https://doi.org/10.1016/C2017-0-03562-0

Haddeland, I., Heinke, J., Biemans, H., Eisner, S., Flörke, M., Hanasaki, N., . . Wisser, D. (2014). Global water resources affected by human interventions and climate change. Proceedings of the National Academy of Sciences of the United States of America, 111(9), 3251-3256. Retrieved November 14, 2020, from http://www.jstor.org/stable/23770678

Hewitt, E. J. (1967). Sand and Water Culture Methods Used in the Study of Plant Nutrition (2nd ed., Vol. 3). doi: $10.1017 / \mathrm{S} 0014479700021852$

Hoagland, D. R., \& Arnon, D. I. (1950). The Water-Culture Method for Growing Plants Without Soil. Berkeley, California: University of California.

Hoover, L. A., Phillip, W. A., Tiraferri, A., Yip, N. Y., \& Elimelech, M. (2011). Forward with Osmosis: Emerging Applications for Greater Sustainability. Environmental Science \& Technology, 45(23), 9824-9830. https://doi.org/10.1021/es202576h

Houston Dynamic. (n.d.). Pump Flow Pulsation - One of the Top Six Pump Vibration Problems. Retrieved September 08, 2020, from https://houstondynamic.com/pump-flow-pulsation-one-of-the-top-six-pumpvibration-problems/\#: : text=In peristaltic pumps, pulsation is,smooth and makes it pulsate.

Jensen, M. H. (1997). Hydroponics. HortScience, 32(6), 1018-1021.

Johnson, D. J., Suwaileh, W. A., Mohammed, A. W., \& Hilal, N. (2018). Osmotic's potential: An overview of draw solutes for forward osmosis. Desalination, 434, 100-120. doi: 10.1016/j.desal.2017.09.017

Jones, E., Qadir, M., Van Vilet, M. T., Smakhtin, V., \& Kang, S. (2019). The state of desalination and brine production: A global outlook. Science of the Total Environment, 657, 1343-1356. doi:10.1016/j.scitotenv.2018.12.076

Khawaji, A. D., Kutubkhanah, I. K., \& Wie, J. (2008). Advances in seawater desalination technologies. Desalination, 221(1-3), 47-69. doi:10.1016/j.desal.2007.01.067

Koutroulis, A. G., Tsanis, I. K., Daliakopoulos, I. N., \& Jacob, D. (2013). Impact of climate change on water resources status: A case study for Crete Island, Greece. Journal of Hydrology, 479, 146-158. doi:10.1016/j.jhydrol.2012.11.055

Kucera, J. (2019). Desalination: Water from water. ProQuest Ebook Central https://ebookcentral.proquest.com Kucera, J. (Ed.). (2014). Desalination: Water from water. Retrieved from https://ebookcentral.proquest.com 
Lambrechts, R., \& Sheldon, M. S. (2019). Performance and energy consumption evaluation of a fertiliser drawn forward osmosis (FDFO) system for water recovery from brackish water. Desalination, 456, 64-73. https://doi.org/10.1016/j.desal.2019.01.016

Lenntech. (n.d.). Osmotic pressure calculator. Retrieved September 29, 2020, from https://www.lenntech.com/calculators/osmotic/osmotic-pressure.htm

Li, N. N., Fane, A. G., Ho, W. S. W., \& Matsuura, T. (Eds.). (2008). Advanced membrane technology and applications. ProQuest Ebook Central https://ebookcentral.proquest.com

Lim, M. M. L., Jørgensen, P. S., \& Wyborn, C. A. (2018). Reframing the sustainable development goals to achieve sustainable development in the Anthropocene--a systems approach. Ecology \& Society, 23(3), 653-671. https://doi-org.libproxy.aucegypt.edu/10.5751/ES-10182-230322

Mandell, A., \& McGinniss, R. (2011, April 19). Desalination Realization. Retrieved October 21, 2019, from https://www.greentechmedia.com/articles/print/guest-post-desalination-realization.

Mahto, A., Aruchamy, K., Meena, R., Kamali, M., Kotrapannavar, N. S., \& Aminabhavi, T. M. (2021). Forward osmosis for industrial effluents treatment - sustainability considerations. Separation and Purification Technology, 254. https://doi.org/10.1016/j.seppur.2020.117568

Middleton, K., \& Toxopeus, M. (1973). Diagnosis and measurement of multiple soil deficiencies by a subtractive technique. Plant and Soil, 38(1), 219-226. Retrieved from http://www.jstor.org/stable/42932324

Nagy, E. (2012). 10 - Nanofiltration. In Basic Equations of the Mass Transport through a Membrane Layer (1st ed., pp. 249-266). London: Elsevier. doi:10.1016/B978-0-12-416025-5.00010-7

Nannarone, A., Toro, C., \& Sciubba, E. (2017, July). Multi-Effect Distillation Desalination Process: Modeling and Simulation. In ECOS 2017 - THE 30TH INTERNATIONAL CONFERENCE ON EFFICIENCY, COST, OPTIMIZATION, SIMULATION AND ENVIRONMENTAL IMPACT OF ENERGY SYSTEMS. Retrieved August 12, 2020, from https://www.researchgate.net/publication/318207357_MultiEffect_Distillation_Desalination_Process_Modeling_and_Simulation

Nashed A, Sproul AB, Leslie G (2014). Water resources and the potential of brackish groundwater extraction in Egypt: a review. J Water Supply. doi:10.2166/aqua.2014.162

Nasr, P., \& Sewilam, H. (2015). Forward osmosis: an alternative sustainable technology and potential applications in water industry. Clean Technologies and Environmental Policy, 17(7), 2079-2090. doi: $10.1007 / \mathrm{s} 10098-015-0927-8$

Nasr, P., \& Sewilam, H. (2015). The potential of groundwater desalination using forward osmosis for irrigation in Egypt. Clean Technologies and Environmental Policy, 17(7), 1883-1895. doi: 10.1007/s10098-0150902-4

Nasr, P., \& Sewilam, H. (2016). Investigating the performance of ammonium sulphate draw solution in fertilizer drawn forward osmosis process. Clean Technologies and Environmental Policy, 18(3), 717-727. doi: 10.1007/s10098-015-1042-6

Navarro-Ortega, A., Acuña, V., Bellin, A., Burek, P., \& Cassiani, G. (2015). Managing the effects of multiple stressors on aquatic ecosystems under water scarcity. The GLOBAQUA project. Science of the Total Environment, 503-504, 3-9. doi:10.1016/j.scitotenv.2014.06.081

Nechifor, V., \& Winning, M. (2018). Global Economic and Food Security Impacts of Demand-Driven Water Scarcity-Alternative Water Management Options for a Thirsty World. Water (20734441), 10(10), 1442. https://doi-org.libproxy.aucegypt.edu/10.3390/w10101442

OECD. (n.d.). Water use in agriculture. Retrieved September 30, 2020, from https://www.oecd.org/environment/water-use-in-agriculture.htm

Organisation, F. E. C. A. D. (2014). Water and climate change adaptation : Policies to navigate uncharted waters. ProQuest Ebook Central https://ebookcentral.proquest.com

Pereira, L. S., Cordery, I., \& Iacovides, I. (2009). Coping with Water Scarcity: Addressing the Challenges. Springer, Dordrecht. doi:10.1007/978-1-4020-9579-5

Phuntsho, S. (2012). Retrieved from http://hdl.handle.net/10453/21808

Phuntsho, S., Lotfi, F., Hong, S., Shaffer, D. L., Elimelech, M., \& Shon, H. K. (2014). Membrane scaling and flux decline during fertiliser-drawn forward osmosis desalination of brackish groundwater. Water Research, 57, 172-182. doi:10.1016/j.watres.2014.03.034

Phuntsho, S., Shon, H. K., Hong, S., Lee, S., \& Vigneswaran, S. (2011). A novel low energy fertilizer driven forward osmosis desalination for direct fertigation: Evaluating the performance of fertilizer draw solutions. Journal of Membrane Science, 375(1-2), 172-181. doi:10.1016/j.memsci.2011.03.038

Phuntsho, S., Shon, H. K., Hong, S., Lee, S., Vigneswaran, S., \& Kandasamy, J. (2012a). Fertiliser drawn forward osmosis desalination: the concept, performance and limitations for fertigation. Reviews in Environmental Science and Bio/Technology, 11(2), 147-168. doi: 10.1007/s11157-011-9259-2 
Phuntsho, S., Shon, H. K., Majeed, T., El Saliby, I., Vigneswaran, S., Kandasamy, J., . . Lee, S. (2012b). Blended Fertilizers as Draw Solutions for Fertilizer-Drawn Forward Osmosis Desalinatio. Environmental Science \& Technology, 46(8), 4567-4575. doi:10.1021/es300002w

Porifera Inc. (2015). Fluxometer User Manual, ver 2.1. Porifera.

Resh, H. M. (2012). Hydroponic food production : A definitive guidebook for the advanced home gardener and the commercial hydroponic grower. Retrieved from https://ebookcentral.proquest.com

Robbins, W. R. (1946). GROWING PLANTS IN SAND CULTURES FOR EXPERIMENTAL WORK. Soil Science, 62(1), 3-22. Retrieved from https://journals.lww.com/soilsci/Citation/1946/07000/GROWING_PLANTS_IN_SAND_CULTURES FOR EXPERIMENTAL.2.aspx

Roson, R., \& Damania, R. (2017). The macroeconomic impact of future water scarcity: An assessment of alternative scenarios. Journal of Policy Modeling, 39(6), 1141-1162. doi:10.1016/j.jpolmod.2017.10.003

Safewater. (2017, January 23). Ultrafiltration, Nanofiltration and Reverse Osmosis. Retrieved August 24, 2020, from https://www.safewater.org/fact-sheets-1/2017/1/23/ultrafiltrationnanoandro

Samir, S. (2018, October 14). Egypt's per capita share of water declines to $570 \mathrm{~cm} 3 /$ year in 2018, Min. Retrieved August 12, 2020, from https://www.egypttoday.com/Article/1/58957/Egypt\%E2\%80\%99sper-capita-share-of-water-declines-to-570-cm3

Santillo, D. (2007). Reclaiming the Definition of Sustainability. Environmental Science and Pollution Research - International, 14, 60-66. doi: https://doi-org.libproxy.aucegypt.edu/10.1065/espr2007.01.375

Shahzad, M. W., Burhan, M., Ang, L., \& Ng, K. C. (2018). Adsorption desalination-Principles, process design, and its hybrids for future sustainable desalination. In V. G. Gude (Ed.), Emerging Technologies for Sustainable Desalination Handbook (pp. 3-34). essay, Elsevier. https://www.sciencedirect.com/.

Shon, H. K., Phuntsho, S., Zhang, T. C., \& Surampalli, R. Y. (2015). Forward Osmosis: Fundamentals and Applications. American Society of Civil Engineers (ASCE). Retrieved November 17, 2020, from https://ebookcentral.proquest.com

Smith, G. S., Johnston, C. M., \& Cornforth, I. S. (1983). COMPARISON OF NUTRIENT SOLUTIONS FOR GROWTH OF PLANTS IN SAND CULTURE. New Phytologist, 94, 537-548. doi: 10.1111/j.14698137.1983.tb04863.x

STEINER, A. (1961). A UNIVERSAL METHOD FOR PREPARING NUTRIENT SOLUTIONS OF A CERTAIN DESIRED COMPOSITION. Plant and Soil, 15(2), 134-154. Retrieved from http://www.jstor.org/stable/42931931

Tayel, A., Nasr, P., \& Sewilam, H. (2019). Forward osmosis desalination using pectin-coated magnetic nanoparticles as a draw solution. Clean Technologies and Environmental Policy, 21(8), 1617-1628. doi: https://doi-org.libproxy.aucegypt.edu/10.1007/s10098-019-01738-5Trejo-Téllez, L. I., \& GómezMerino, F. C. (2012). Nutrient Solutions for Hydroponic Systems. In Hydroponics - A Standard Methodology for Plant Biological Researches. doi: 10.5772/37578

The World Bank. (2020, May 8). Water in Agriculture. https://www.worldbank.org/en/topic/water-inagriculture.

Traitler, H., Dubois, M. J. -., Heikes, K., Petiard, V., \& Zilberman, D. (2018). Megatrends in food and agriculture : Technology, water use and nutrition. ProQuest Ebook Central https://ebookcentral.proquest.com

UN. (n.d.). Climate Change. Retrieved August 07, 2020, from https://www.un.org/en/sections/issuesdepth/climate-change/

United Nations. (2015). The Sustainable Development Agenda - United Nations Sustainable Development. Retrieved April 26, 2020, from https://www.un.org/sustainabledevelopment/development-agenda/

UN-Water. (n.d.). Water and Climate Change. Retrieved August 5, 2020, from https://www.unwater.org/waterfacts/climate-change/.

UN-Water. (n.d.). Water Quality and Wastewater. Retrieved August 5, 2020, from https://www.unwater.org/water-facts/quality-and-wastewater/.

UN-Water. (n.d.). Water Scarcity. Retrieved October 5, 2019, from https://www.unwater.org/waterfacts/scarcity/.

UN-Water. (n.d.). Water, Food and Energy. Retrieved August 5, 2020, from https://www.unwater.org/waterfacts/water-food-and-energy/.

USDA. Hydroponics. National Agricultural Library. https://www.nal.usda.gov/afsic/hydroponics.

Vörösmarty, C., Green, P., Salisbury, J., \& Lammers, R. (2000). Global Water Resources: Vulnerability from Climate Change and Population Growth. Science, 289(5477), 284-288. Retrieved November 14, 2020, from http://www.jstor.org/stable/3077580 
Wang, L. K., Chen, J. P., Hung, Y., \& Shammas, N. K. (Eds.). (2010). Membrane and desalination technologies. ProQuest Ebook Central https://ebookcentral.proquest.com

Warsinger, D. M., Mistry, K. H., Nayar, K. G., HyungWon Chung, \& V., J. H. L. (2015). Entropy Generation of Desalination Powered by Variable Temperature Waste Heat. Entropy, 17(11), 7530-7566. https://doiorg.libproxy.aucegypt.edu/10.3390/e17117530

Wenten, I. G., \& Khoiruddin. (2016). Reverse osmosis applications: Prospect and challenges. Desalination, 391, 112-125. doi: 10.1016/j.desal.2015.12.011

Woldai, A. (2016). Multi-Stage Flash Desalination. Boca Raton: CRC Press, https://doiorg.libproxy.aucegypt.edu/10.1201/b18664

World Vision. (2018). Global water crisis: Facts, FAQs, and how to help. Retrieved November 14, 2020, from https://www.worldvision.org/clean-water-news-stories/global-water-crisis-facts

Zare, S., \& Kargari, A. (2018). Membrane properties in membrane distillation. In V. G. Gude (Ed.), Emerging Technologies for Sustainable Desalination Handbook (pp. 107-156). essay, Elsevier. https://www.sciencedirect.com/.

Zhang, J., Loong, W. L., Chou, S., Tang, C., Wang, R., \& Fane, A. G. (2012). Membrane biofouling and scaling in forward osmosis membrane bioreactor. Journal of Membrane Science, 403-404, 8-14. doi:10.1016/j.memsci.2012.01.032

Zou, S., Qin, M., \& He, Z. (2019). Tackle reverse solute flux in forward osmosis towards sustainable water recovery: Reduction and perspectives. Water Research, 149, 362-374. doi:10.1016/j.watres.2018.11.015 
Figures

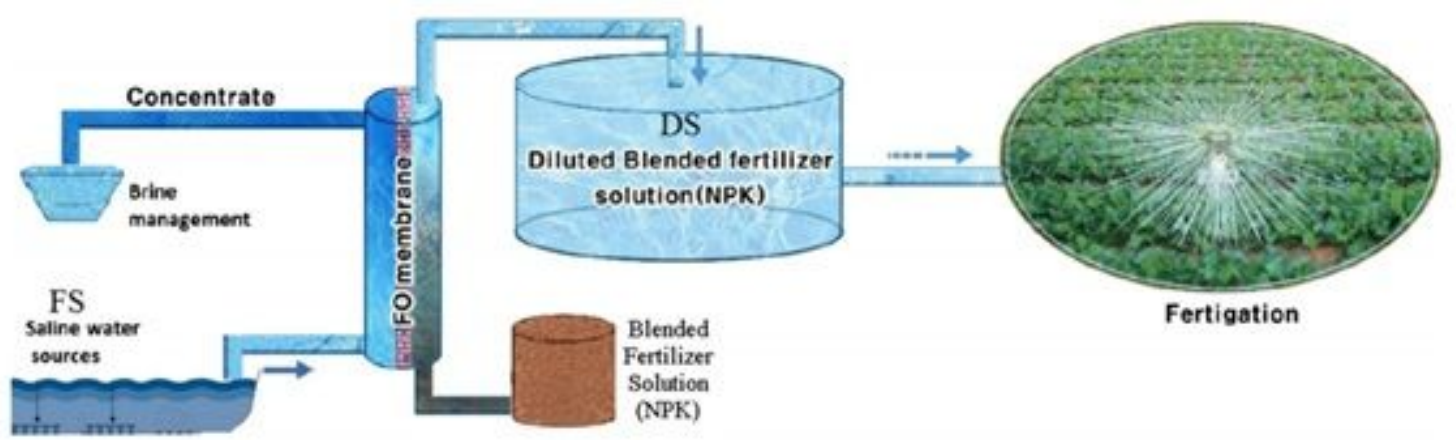

Figure 1

Standard FDFO Setup (Phuntsho et al., 2012)

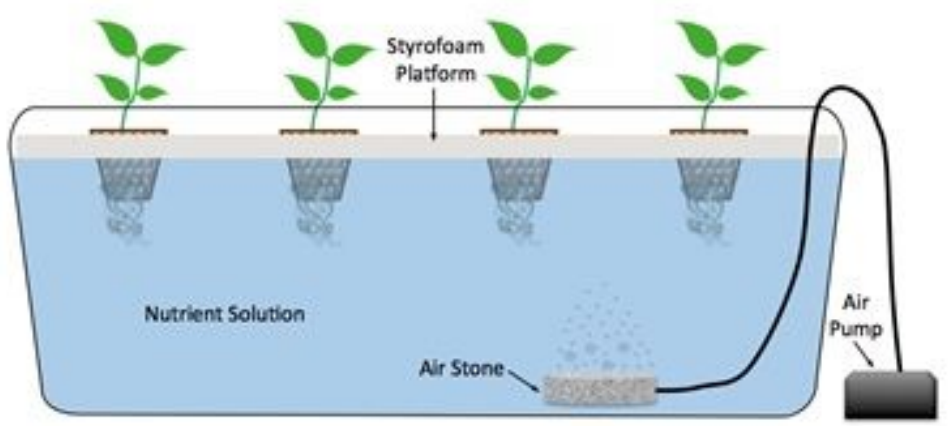

Figure 2

Schematic Diagram of Hydroponic System (Designer Water, n.d.)
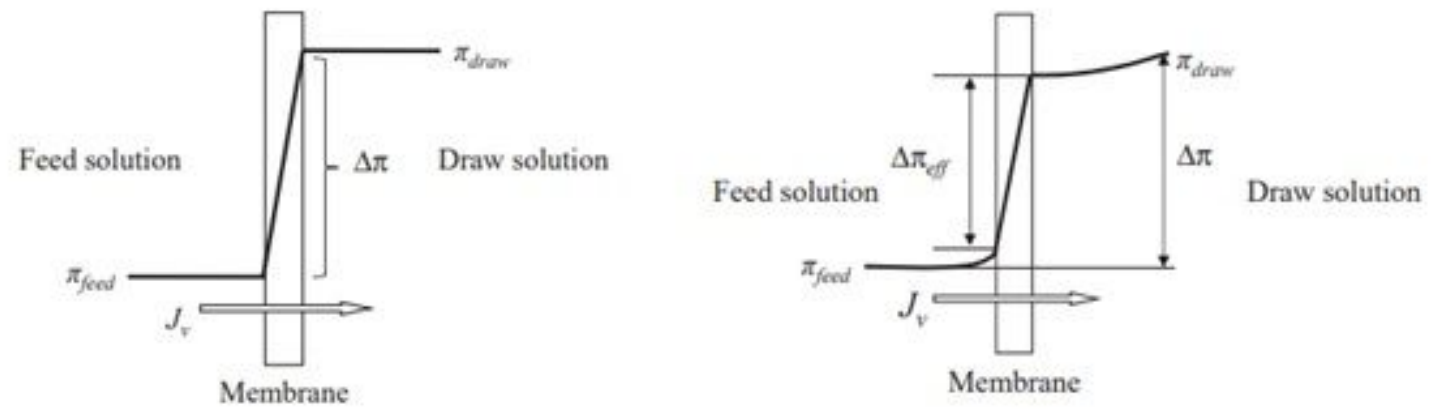

Figure 3

Osmotic Pressure Profile across the FO Membrane without (left) and with (right) Presence of ECP (Shon et al., 2015) 


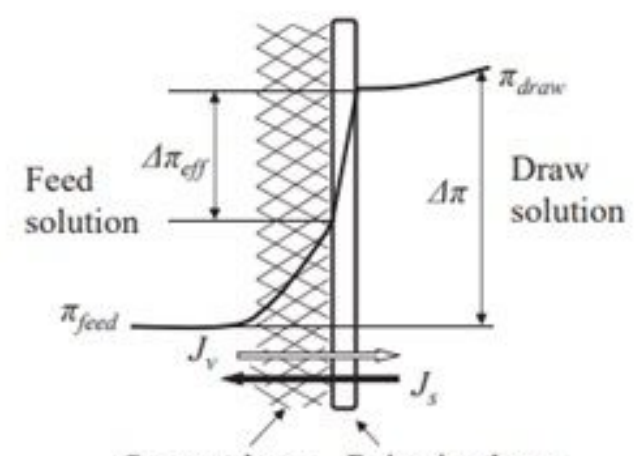

Support layer Rejection layer

(a)

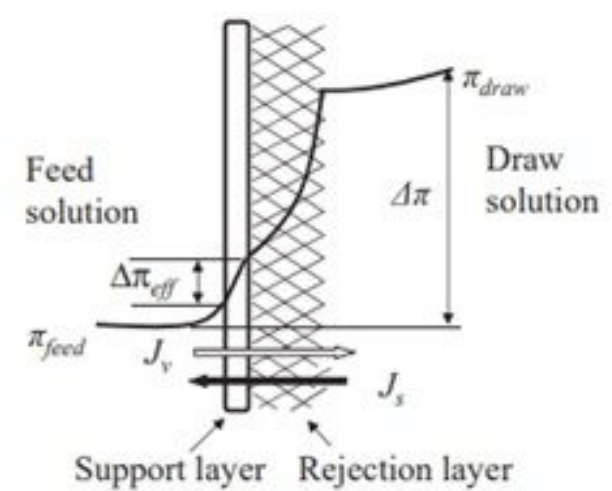

(b)

\section{Figure 4}

Osmotic Pressure Profiles Across an FO Membrane in the (a) AL-DS and (b) AL-FS orientations (Shon et al., 2015)

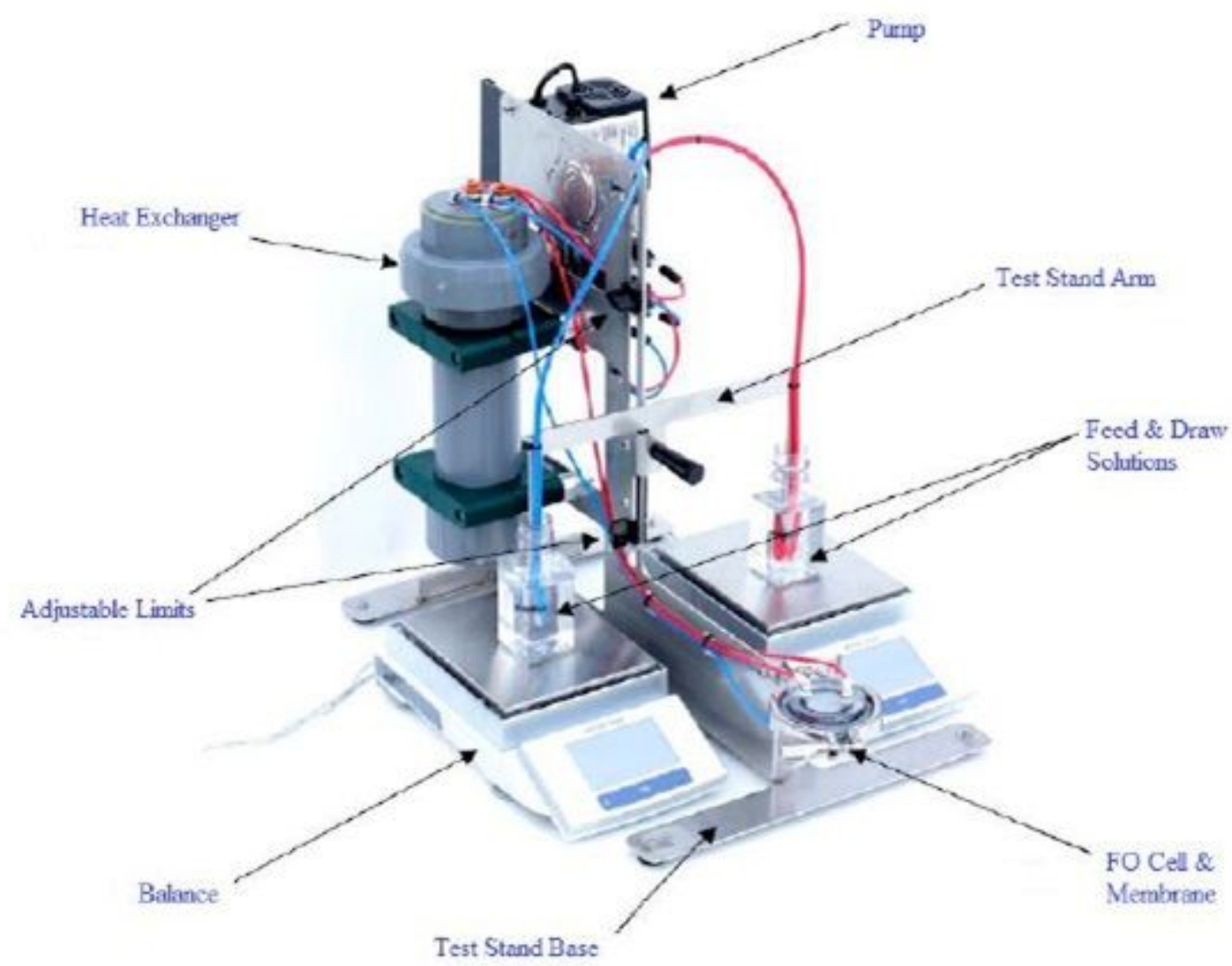

Figure 5

Bench-scale Crossflow Filtration Unit (Porifera Inc., 2015) 


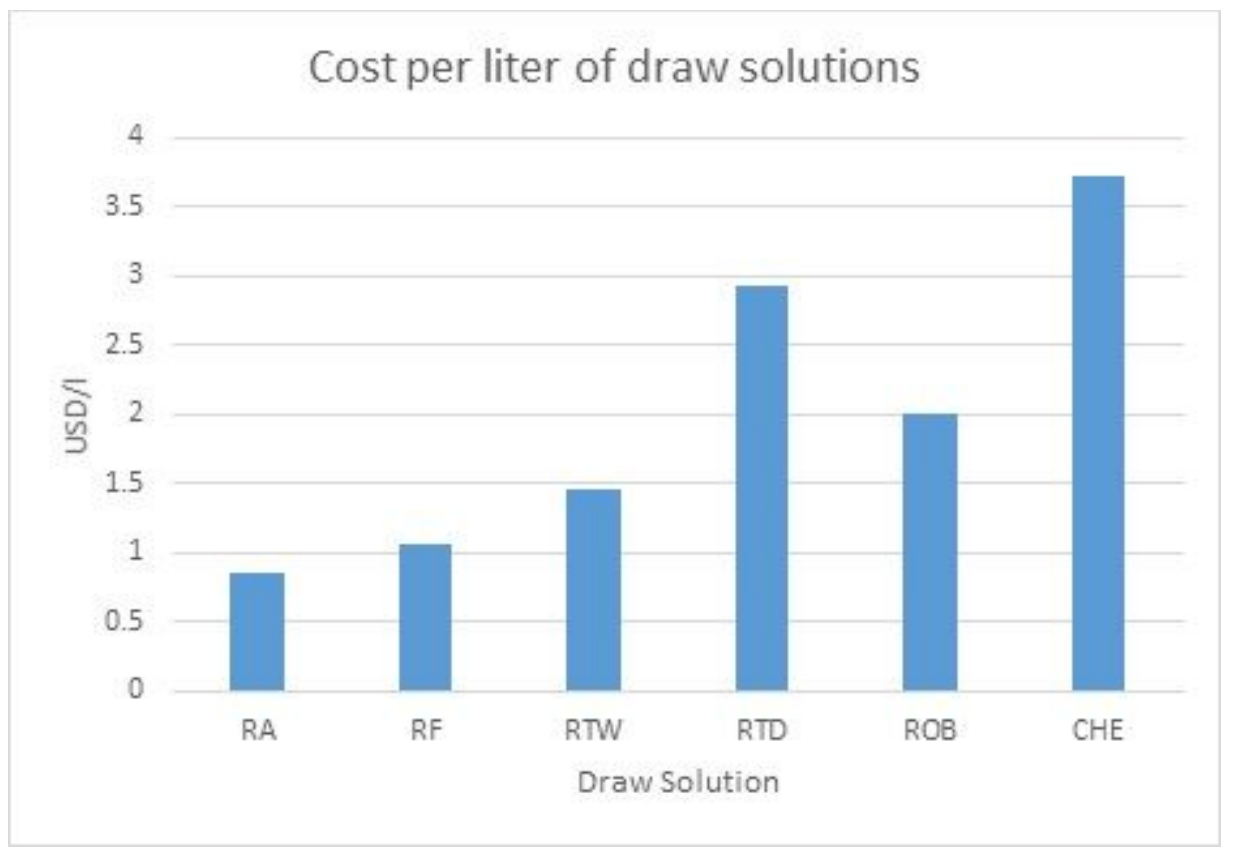

Figure 6

Cost per liter of draw solutions

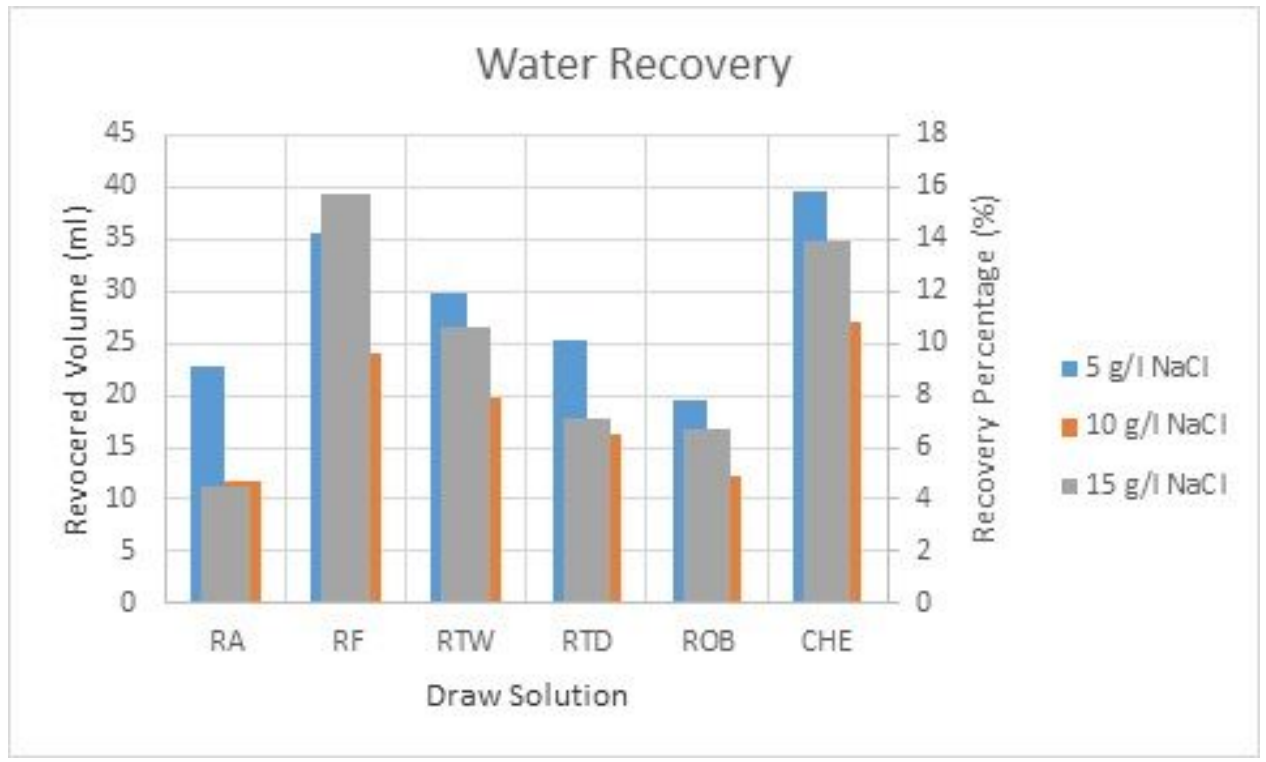

Figure 7

Water Recovery Volume \& Percentage 


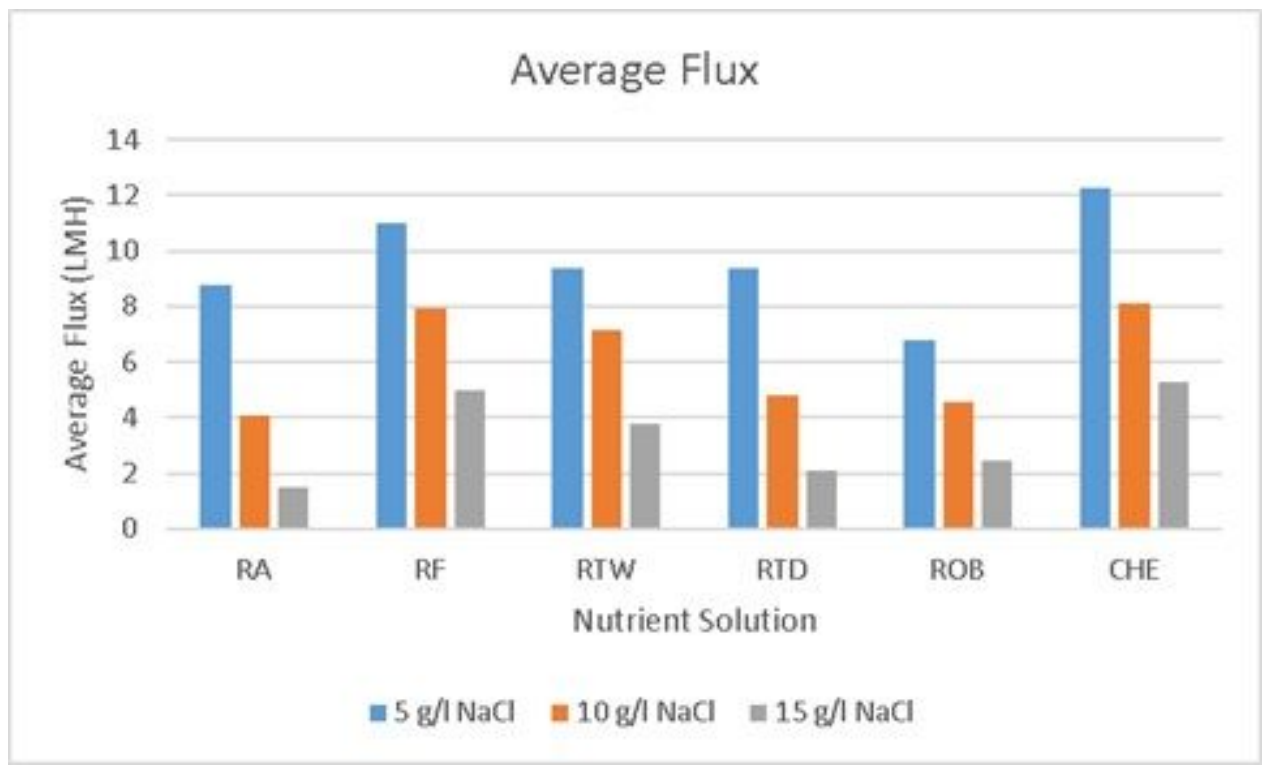

Figure 8

Average Flux

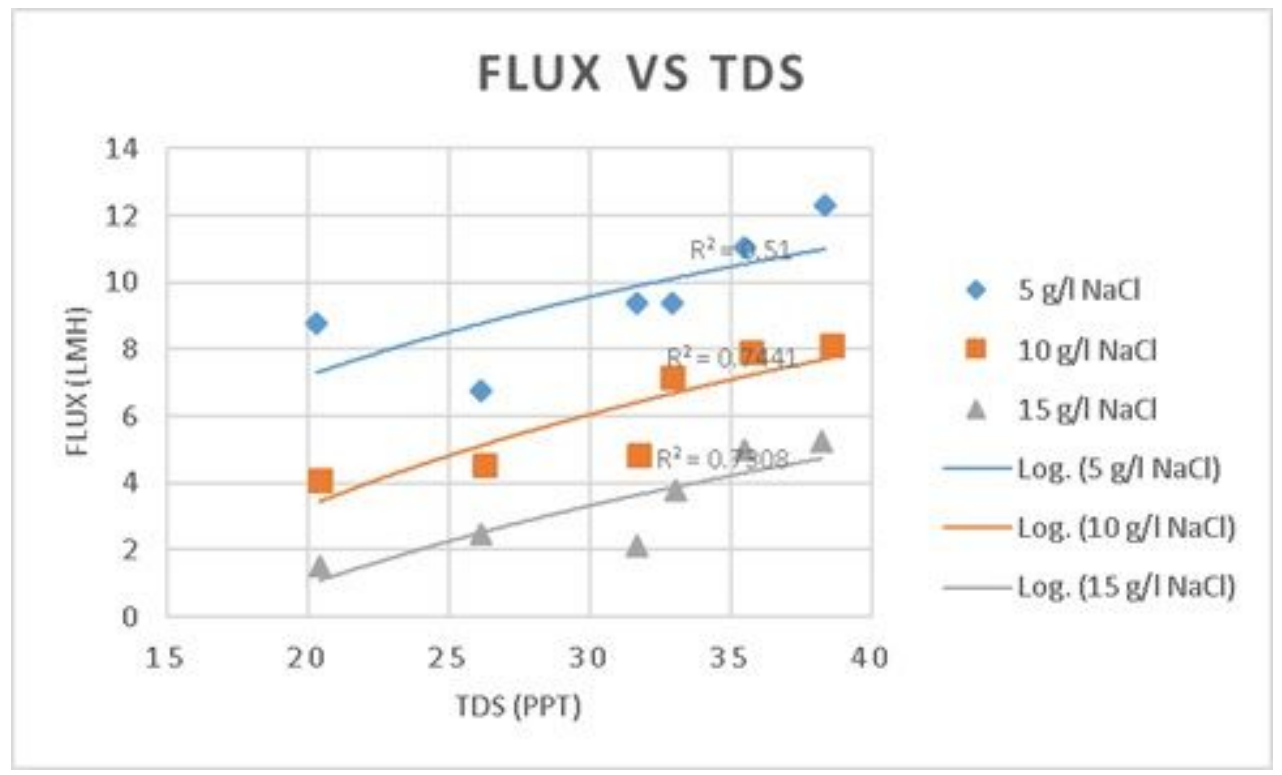

Figure 9

Flux vs TDS 


\section{$5 \mathrm{G} / \mathrm{L}$ NACL}

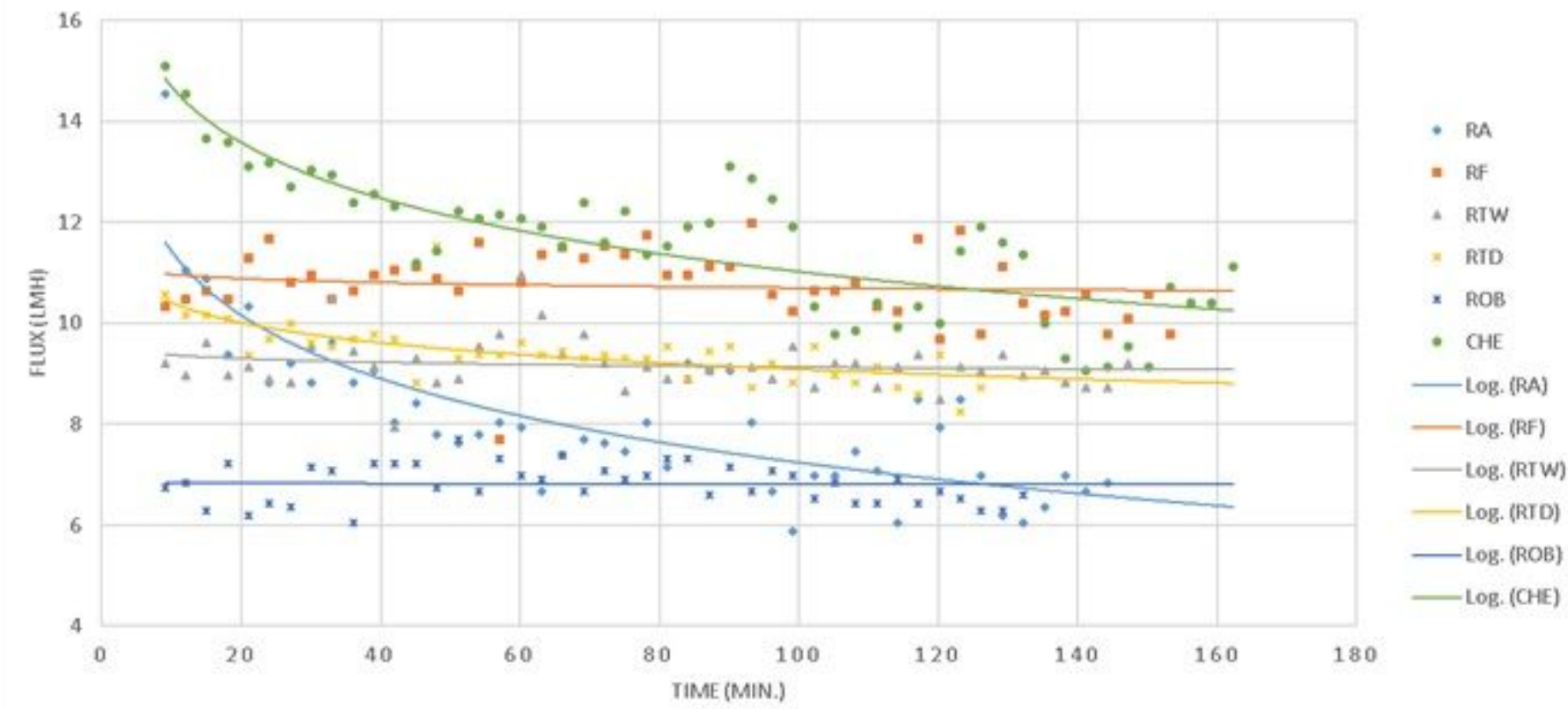

Figure 10

Flux for $5 \mathrm{~g} / \mathrm{l} \mathrm{FS}$

$10 \mathrm{G} / \mathrm{L}$ NACL

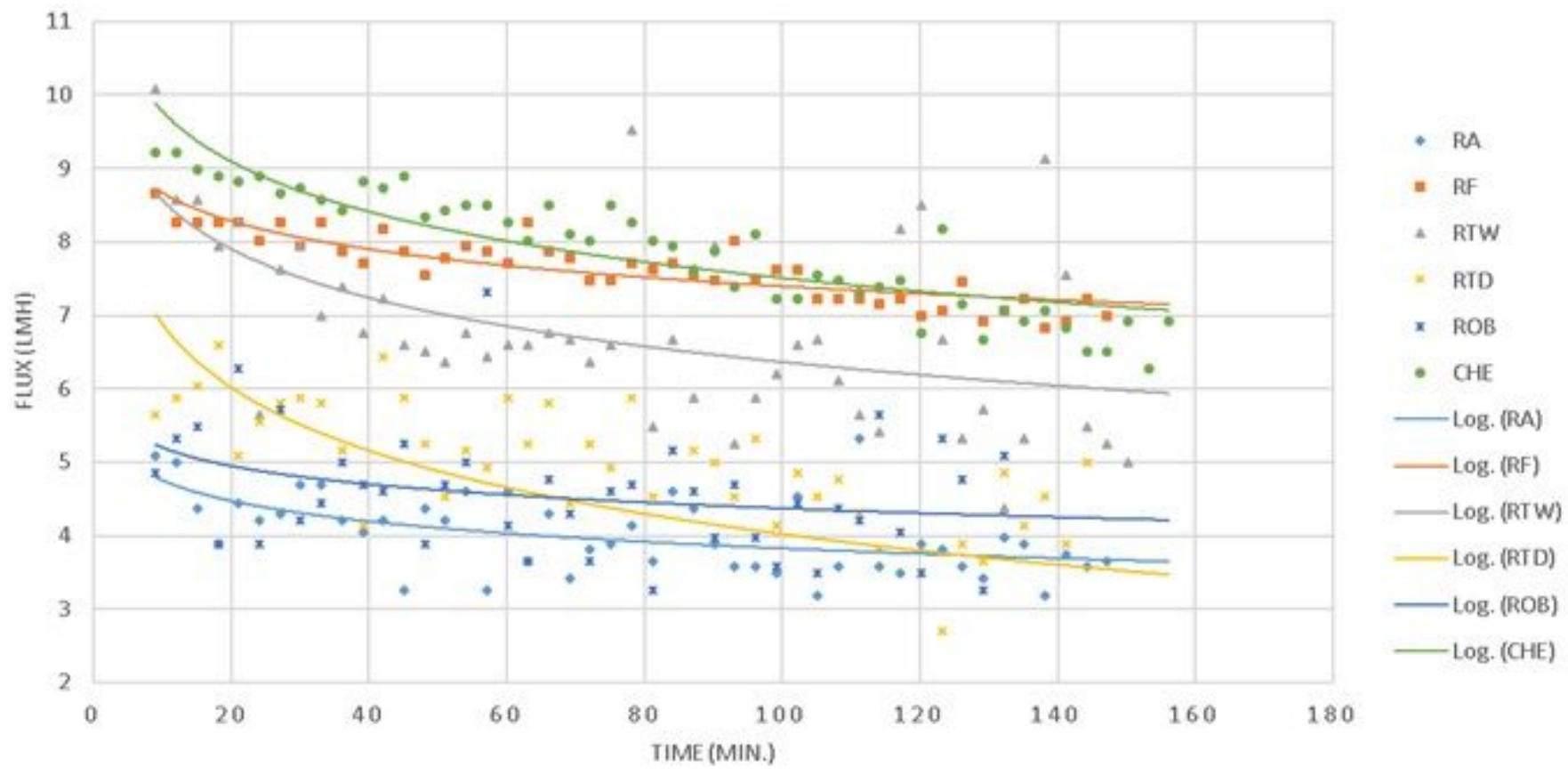

Figure 11

Flux for $10 \mathrm{~g} / \mathrm{l} \mathrm{FS}$ 


\section{$15 \mathrm{G} / \mathrm{L}$ NACL}

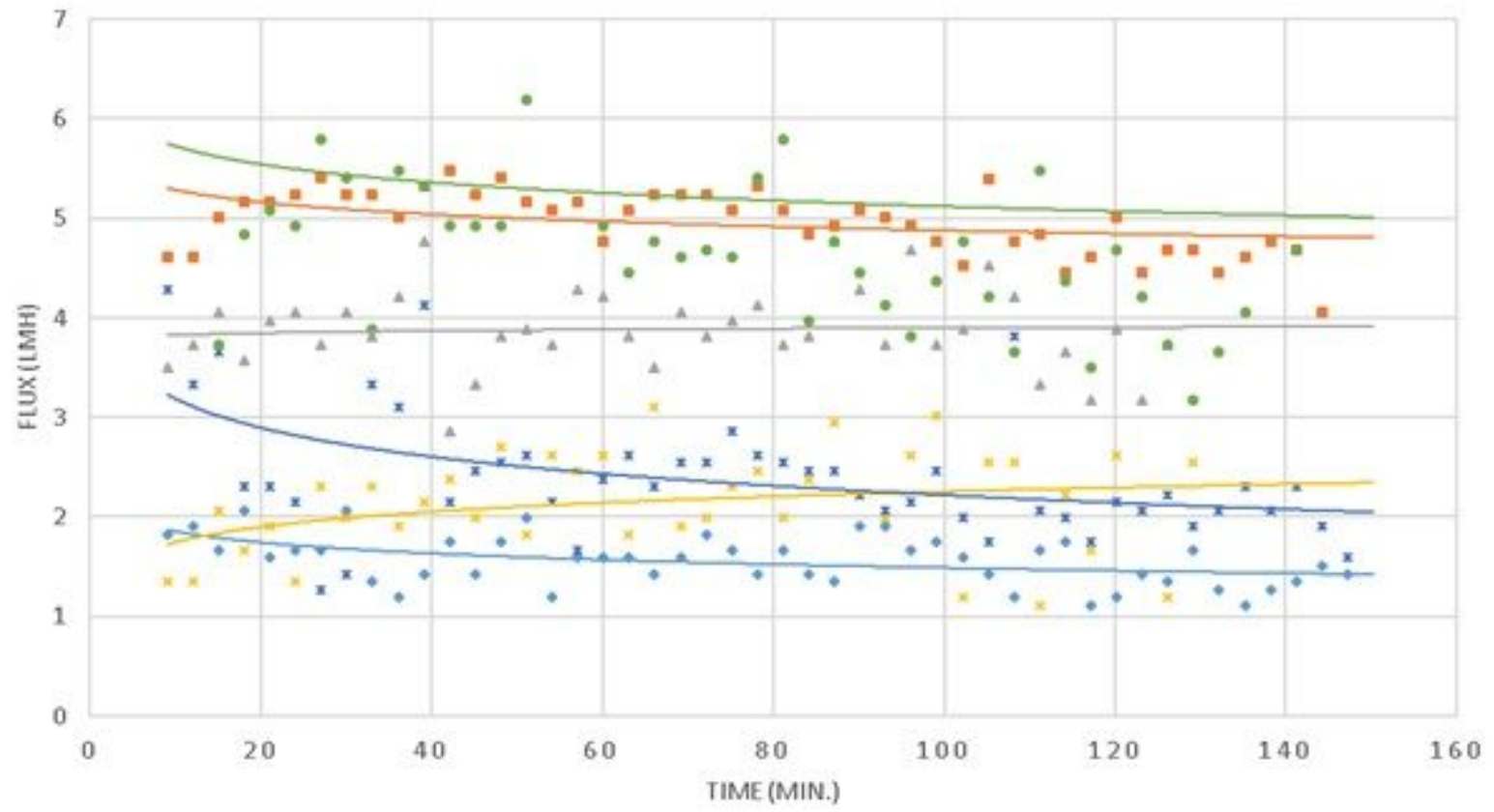

- RA

- RF

4 RTW

$\times$ RID

$\times$ ROB

- CHE

- Log. (RA)

- Log. (RF)

- Log. (RT W)

- Log. (RTD)

- Log. (ROB)

- Log. (CHE)

Figure 12

Flux for $15 \mathrm{~g} / \mathrm{I} \mathrm{FS}$

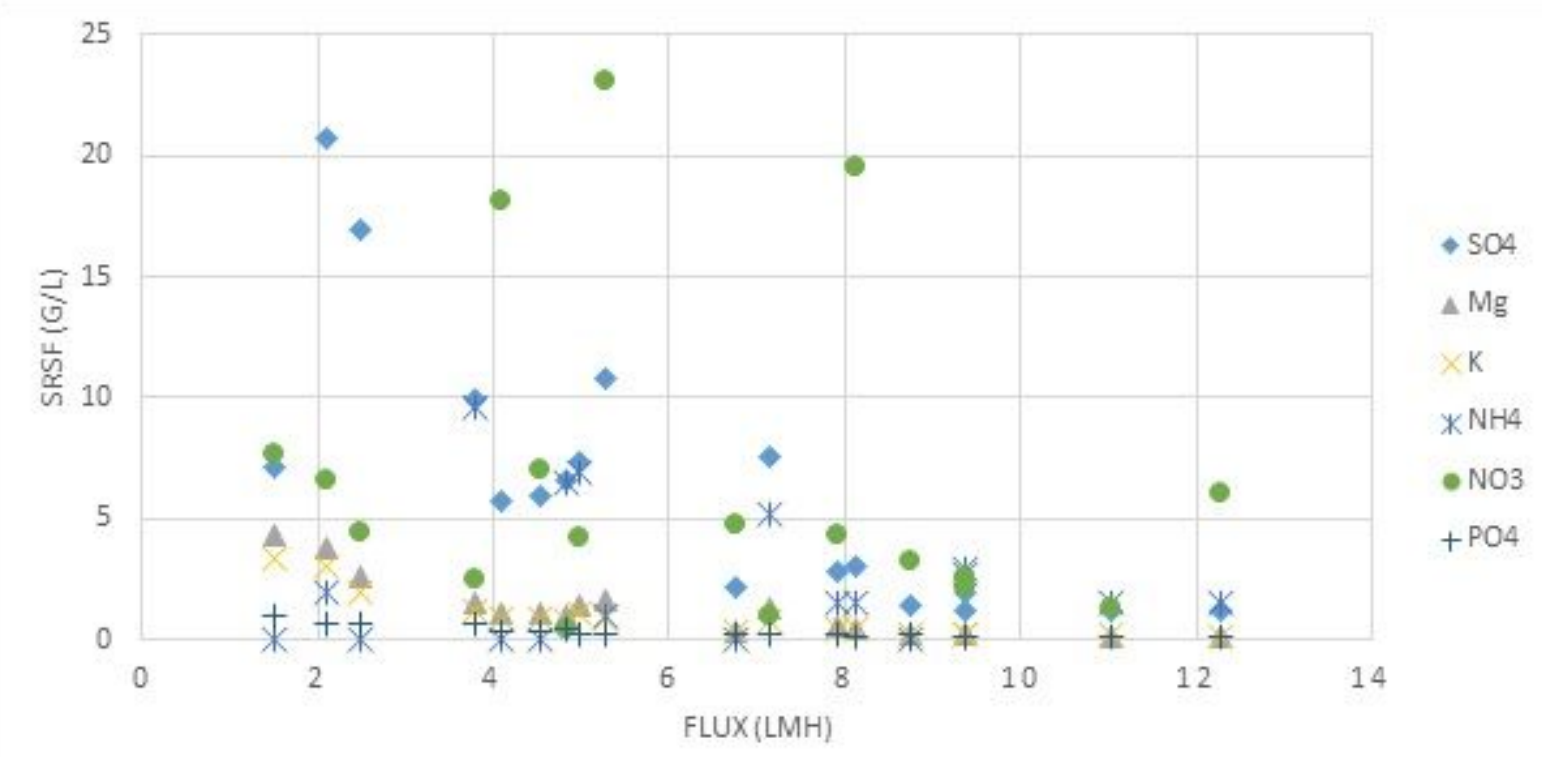

Figure 13

Overview of SRSF of DS ions 

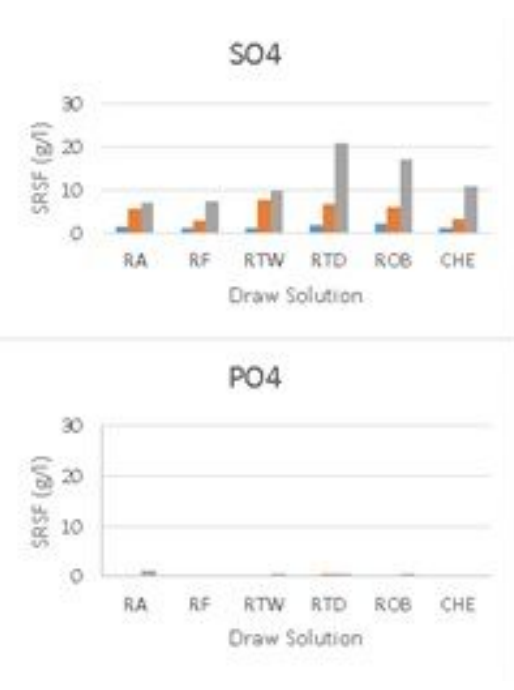

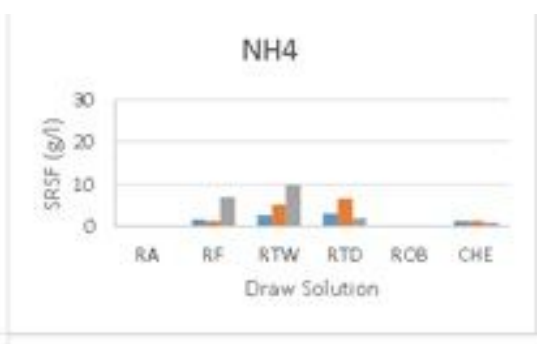

K

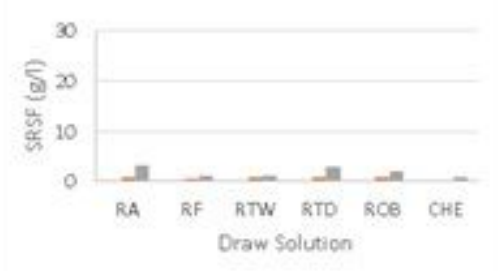

NO3

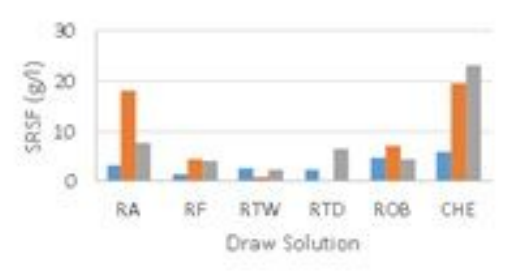

\section{Figure 14}

Comparison between SRSF of DS ions

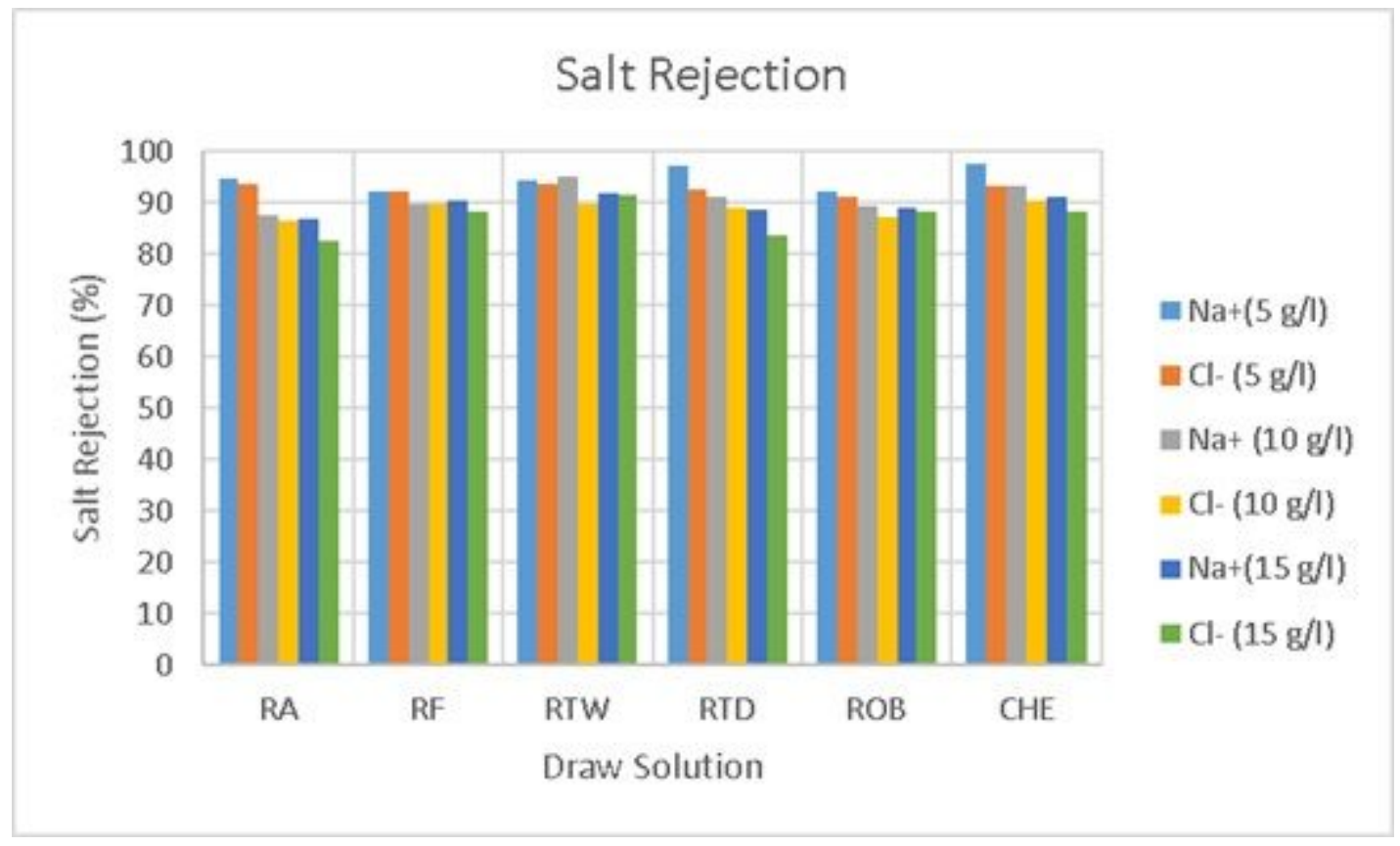

\section{Figure 15}

Forward rejection of FS ions for the different DS solutions

\section{Supplementary Files}

This is a list of supplementary files associated with this preprint. Click to download.

- ManuscriptHydroNutSolESPRTables.pdf 